\title{
Needs Analysis to Develop Effective Vocabulary Instruction for Saudi EFL Context
}

\author{
Dr. Anas Almuhammadi \\ English Language Institute, King Abdul Aziz University, Jeddah, KSA
}

Received: February 21, 2020

Accepted: March 5, 2020 Published: March 6, 2020

doi:10.5296/ijele.v8i1.16619

URL: https://doi.org/10.5296/ijele.v8i1.16619

\begin{abstract}
Teaching vocabulary to EFL learners is thought to be an integral part which involves not only the meaning and closer definition of the words, but also the correct use in the right contexts. Considering the need of the vocabulary, Saudi EFL context has largely focused on vocabulary teaching by setting various standards for different academic levels of the students. The present study aims to investigate the techniques employed by the EFL teachers in Saudi Arabia to teach vocabulary and the factors that affect the process. Qualitative research was adopted by employing semi-structured interviews from $10 \mathrm{EFL}$ teachers working in a university in Saudi Arabia. The data was analyzed using thematic analysis. The data generated four major themes including aspects of vocabulary development, decontextualizing techniques, semi-contextualizing techniques and fully contextualizing techniques. The findings show that EFL teachers are aware of various techniques to teach vocabulary; however, they fail to implement those techniques in EFL classes for various reasons which include workload, test-driven curriculum, busy schedules and so forth. The study found that EFL teachers do not encourage the contextualizing technique in the class; besides, the EFL learners rely heavily on traditional dictionaries, flashcards and rote-learn and memorize the word lists. Based on the findings, the study recommends that the EFL teachers need to reassess their techniques presently used by them in order to help the EFL learners improve their vocabulary in context.
\end{abstract}

Keywords: Vocabulary, de-contextualization, rote-memorization, L2 instruction 


\section{Background}

Since the inception of teaching English in KSA in 1927, vocabulary teaching practice has become the conventional part of Saudi education system (Assah, 1969, cited in Al-Hazemi, 1993). In the matter of vocabulary teaching practice and research in Saudi Arabia, the Ministry of Education (MoE) has made it mandatory for high school students to learn around 3000 words through vocabulary before leaving school. Though the research has questioned whether most of the Saudi Arabic native speaker students are able to achieve this target in vocabulary development. Two different studies have investigated Saudi students' vocabulary knowledge: Al-Hazemi (1993) and Al-Bogami (1995). These two investigations showed that Saudi school students have low and insufficient vocabulary knowledge. Accordingly, Al-Hazemi (1993) maintains that EFL learners scored between 800 and 2000 words with a mean score of around 1000 vocabulary words. Al-Bogami's (1995) research stands in favor of Al-Hazemi's and maintains that Saudi students perform poorly in vocabulary size examination. This shows that most of the learners leave high school with vocabulary knowledge that's insufficient and ineffective for communication (Nation, 2001). If students' learning in schools is insufficient, this will cost in the study of English at university level. It is not unexpected to discover low vocabulary size among students at universities, while it might be anticipated that university students would be a sub-group of the most able school students. Less vocabulary knowledge would affect learners' growth in their higher education study and place a higher learning burden on the students to increase in the levels of knowledge projected to university graduates. Evidences are found of this since it emerges as lexical insufficiency restricting the reading and comprehending of the texts used at undergraduate level (Al-Homoud \& Schmitt, 2009).

Over last few decades, there has been much improvement in research on vocabulary development and testing. Several research studies maintain that learning vocabulary is foundational for learning language skills and thus considered it a very important part of language knowledge (Daller, Milton \& Treffers-Daller, 2007). The recent literature on vocabulary development shows a close relation between EFL learners' knowledge about vocabulary, communication and reading comprehension. Shen (2008) notes that EFL learners' knowledge of vocabulary directs learning of all four skills which is supported by a study (Nation, 1990) telling more vocabulary size leads to better reading performance. Effective vocabulary building is deemed at the center of foreign language learning.

\subsection{Principles of Teaching Vocabulary}

To align teaching vocabulary with the students' needs, there are certain principles that should be looked into in this process. Nation (2001) notes nine different aspects in vocabulary which are likely to be taught to language learners. These include spoken form, written form, and part of the word with some meaning, concepts of the word mean things it is associated with, connotative attributes of the word, grammatical function of the word, collocative use, register and frequency of the word. Besides, Nation (2015) suggested five major principles which are helpful in teaching vocabulary: 1) avoiding complication in explanation of the word and being as simple as possible b) developing relationship of the words with the past knowledge i.e. analogies 3) relying on oral and written presentation 4) focusing on the words which are 
somehow familiar 5) informing the students about the frequency of the word so as to be focused accordingly.

Oxford and Crookall (1990) categorized vocabulary techniques into four to understand vocabulary teaching methods in more detail. These techniques include 1) decontextualizing word lists, flashcard and dictionary use 2) semi-contextualizing which refers to word grouping, association, visual imagery, aural imaginary, keyword, physical response and semantic mapping 3) fully-contextualizing which includes reading, listening, speaking and writing 4) adaptable - structured reviewing.

Considering these four categories of teaching vocabulary, the research shows that to learn words, the learner has to rely on all of them which are equally effective. In this regard, Hague (1987), McWilliam (1998), Richards \& Singleton (1999) and Stahl (2003) maintain that in order for EFL learners to attain native-like proficiency, they need to have more exposure to target language vocabulary. Therefore, vocabulary teaching process should be a dynamic process taking mental lexicon of the learners into consideration. To do so, strategies and techniques are necessary to be used to facilitate lexical acquisition. Zimmerman (1997) notes that many skills are required to help learners learn words. This shows that vocabulary learning is not an isolated activity.

\subsection{Vocabulary Teaching Practice and Research in Saudi Arabia}

Altyari (2017) notes that the deficiency of vocabulary knowledge among Saudi students weakens their linguistic performance in English. The researcher points out two facts that contribute negatively to vocabulary uptake and lexical development among Saudi students in public high schools. The participants included thirty-five students from different education levels and nine male Saudi EFL teachers EFL at intermediate and secondary schools. The results disclose that vocabulary strategies were ineffectively used by the student-participants as they mainly depended on using a bilingual dictionary or asking others to know the meanings and so on. Similarly, the results also show insufficient recycling of the vocabulary items and arrangements of all aspects of the vocabulary knowledge. Elttayef and Hussein (2017) explored the complexities that teachers face in teaching English to the Arab learners. The investigation found that the learners have inadequate basic knowledge despite being taught English language in schools. Later, it points out the lack of attention on the part of the teachers in highlighting the significance of English in classrooms. It also declares that the teachers' role in teaching English is doubled because their students depend on them with the expectations that they would make students learn English language soon. This study claims that the sociocultural background also affects teaching English to the Arab learners who attend English classes mostly to pass the examinations. The researchers (ibid) argue that with this poor background, students face complexities later at college and university levels when they engage themselves in specialized fields. This study concludes that the learners encounter difficulties in practicing language and communication skills such as listening, speaking (Elttayef \& Hussein, 2017).

Another study of Alqahtani (2015) proclaims that the learning of vocabulary is viewed as an important characteristic of the second language learning. This research on vocabulary enlightens teaching techniques employed by teachers while teaching vocabulary. As a 
teacher-researcher, according to Alqahtani (ibid) the students in Saudi are taught grammar rules more than the vocabulary. Baniabdelrahman and Al-shumaimeri (2014) by using the cluster sampling methods observed the techniques adopted by the first-year students at a Saudi university to guess the meanings of unknown words in reading a text. The participants belong to the preparatory-year at King Saud University. The study claims that most students were unable to use the strategies for guessing the meaning of an unseen word. The results of this study encourage the teachers to, practically, train the students in using various strategies to derive correct meanings of new vocabulary.

In Saudi Universities, the EFL learners are found to face several challenges in vocabulary learning and retaining it for the appropriate use. As a result, they have low proficiency in English as a foreign language. EFL teachers play a key role in EFL classrooms and their cognition determines their instructional strategies affecting L2 vocabulary acquisition either positively or negatively. The study looks deeper into the types of vocabulary teaching techniques, the challenges and difficulties to practice innovative strategies. On the basis of these research questions, the needs analysis is done to develop a better model of teaching vocabulary practices at Saudi EFL context. To achieve the objectives, the study seeks to answer the following questions

1. What types of vocabulary teaching strategies are employed by EFL teachers?

2. What are the factors that hinder the practice of vocabulary teaching strategies in EFL classes?

3. What are the professional needs of EFL teachers to better teach vocabulary to their students?

\section{Research Design}

Drawing on qualitative research design, the present study recruited university teachers for semi-structured interviews by employing available sampling method. The participant-teachers are categorized as native speakers, Saudi EFL teachers and Non-Saudi (non-native) EFL teachers; the present researcher gathered insights from 10 EFL teachers from all the categories to have a representative sample.

\subsection{Data Analysis Technique}

The interview data were analyzed using thematic analysis which is used in qualitative research to categorize the comprehensive qualitative data into codes, categories and themes. In present study, four themes emerged from interviews including aspects of vocabulary development, de-contextualizing techniques, semi-contextualizing techniques and fully contextualizing techniques. 


\section{Results and Discussion}

In the present study, 10 EFL teachers were interviewed. This section presents the findings of the interviews based on the themes and sub-themes that were generated from the transcription of the interviews. The first theme relates to 'aspect of vocabulary development'; the second theme is de-contextualizing techniques; the third refers to semi-contextualizing while the last theme is related to fully contextualizing techniques.

\subsection{Aspects of Vocabulary Development}

In response to subthemes related to meaning of the vocabulary, the majority of the EFL teachers unanimously believed that L1 does have the loan word but to a little extent with a slight difference in meaning. Grammatically, the word is patterned and can be categorized for identification. One of the teachers commented that:

...to memorize the words is challenging. Since the words are not practiced considering context, the learners find it difficult to learn. A few lessons integrating story and dialogue practices are not sufficient. It has been observed that most students focus on rote-learning and memorization of the words instead of finding the contextual meaning. And collocative and grammatical functions of the vocabulary are less focused.

These findings have been supported by several researchers since they believe that paired lists are inadequate for vocabulary learning (Carrell, 1984; Hudson, 1982; Swaffar, 1988). In Carrel's words, a list of news or unfamiliar words from any text with closer meaning may not ensure the successful learning of vocabulary. Despite that decontextualizing of the words, the flashcards are popularly used in classes especially for vocabulary self-assessment. As one teacher commented that:

...the dominant use of dictionary to look up the meaning of the words has caused de-conxtualization of the meaning.

\subsection{Decontextualizing Techniques}

In response to 'decontextualizing techniques' which the EFL teachers were aware of, they maintained that at the Saudi university, the EFL teachers teach vocabulary solely based on word lists, flash cards and dictionary use. For instance, one teacher stated that:

When we teach reading, we encourage students to make a list of individual words from the text being taught to them. And the students then look for their meanings in dictionary.

In a similar vein, when EFL vocabulary is tested through individual meanings and definition of the words with their use in sentences. As a result, they fail to learn collocative use of words and context-specific meanings.

\subsection{Semi-Contextualizing Technique}

Besides other two techniques, 'semi-contextualizing technique' also emerged as an important 
theme from interview data which involves various subthemes such as word grouping, word association, visual and aural imagery, keyword, physical response, physical sensation and semantic mapping.

There are several semi-contextualizing techniques for EFL vocabulary learning. These techniques involve associations with other words or sound similarities; however, in some cases, the techniques employed are extra-linguistic which include visual and aural imagery, physical response and sensation. An EFL teacher is of the view that:

A few learners look for semi-contextualizing factors; for instance, they do try to find out possible association of the word, or look for analogies. And this is done by very few students who have an aptitude for language learning.

According to Carrell (1984), students rely on semantic mapping which helps them to develop analogies, show comparisons and use metaphors to fill the gap as to what they know before about the concept and what else they need to know.

\subsection{Fully Contextualizing Techniques}

Learning any language cannot be detached from the context where it is spoken and used. EFL teachers responded that learning a language has to be context-situated. In the context of English language teaching, they find it challenging to transfer the language skills to EFL learners fully since the context to them is not fully known. And, they thus fail to contextualize L2 teaching activity. One teacher commented that:

It is much difficult to situate L2 content in the context since it reflects their values and social practices. Sometimes, we find it difficult to understand fully.

EFL reading requires rich materials including articles, stories, newspapers, books, magazines, letters and also advertisements as stated by (Crookall \& Watson, 1985). The research shows that reading helps the EFL learners to absorb vocabulary and retain it since the learners see the real use of words in the contexts where they are used. Some participant- teachers argue that writing and speaking skills also facilitate vocabulary learning. Thus, it is suggested that the learners may be exposed to more target language input and communicative contexts. That is possible through various activities in the EFL classrooms such as gaming, group formations, project-based learning. It is also advised to encourage students to write and speak English in a naturalistic way.

The EFL teachers stated that they prioritize contextual strategy as much as they can since it is essential for EFL vocabulary learning. They were of the view that the EFL learners consciously look up the use of words in the context and that helps them to teach vocabulary more effectively. On the other hand, some teachers preferred co-operative strategy as they thought that this is more useful in retaining words. However, this was found less practical in the classroom as the observations suggest in the light of the views of the participants. 
According to Stahl (1999), context clues play a significant role in vocabulary learning. EFL learners somehow rely on context clues during vocabulary learning. EFL teachers, as they responded, also promote this technique in EFL classes. Clues may be in the form of giving synonyms, closer definition, opposites, or sometimes the examples related with the word. Thornbury (2002) states that EFL vocabulary can best be taught using clues in the class.

\section{Conclusion and Implications}

Although teachers know about a variety of strategies for teaching vocabulary, they are not able to employ a wide range of techniques due to number of factors such as nature of the textbook, level of the learners and time constraints to cover the course book. Defending teachers' views, it is observed that teachers have a heavy workload and they are too busy with different assignments. The findings of previous research correspond with the views of the teachers interviewed that the use of strategies should not be static but change dynamically in accordance with the stages and levels of learning. Teachers agree that various teaching techniques are neither 'bad' nor 'good '. and they think these techniques have both positive and negative sides. Teachers agreed that a single method won't help achieve the purpose of acquiring vocabulary (Schmitt, 2000).

As the results show there is a need to help teachers realize the significance of vocabulary teaching and making them aware of a broad range of vocabulary teaching methods and techniques. If teachers use a broad range of methods in their classroom, learners will get to know a broad range of strategies and they then would use them for their vocabulary acquisition. But, currently teachers employ a restricted set of methods. In this regard, keeping in view the needs of instructors, professional development sessions should be arranged to introduce teachers to a broad range of current practices of teaching vocabulary. In this way, they would get to know the significance of such methods and evaluate their effectiveness for their immediate context. This will help transform the common beliefs of teachers as well as their learners about vocabulary acquisition. In this way, they will be able analyze and evaluate the usefulness of strategies for various aspects of vocabulary learning.

One of the factors which needs much attention in the practice of teaching vocabulary at Saudi EFL context is to focus on the techniques learners adopt to comprehend new words, learn new information and retain it (O'Malley and Chamot 1990). It is recognized that teaching broadens learners' vocabulary and their knowledge of words, but it is very important to help learners choose the appropriate strategies and techniques for their vocabulary development. That's why it is emphasized again that there is no need to search the single best strategy for vocabulary development. Instead, learners are trained by the teachers to make a sensible use of a variety of strategies useful for them. This could be possible through effective teaching which focuses more on developing handy skills and beneficial practices instead the development of content and knowledge (Bialystok 1985). By doing so, teachers can help their students develop ability of metacognitive awareness to choose strategies themselves.

L2 instruction may be designed considering learning style preferences which are likely to 
affect vocabulary learning. Moreover, individual differences besides cultural and ethnic play an important role in vocabulary learning and thus must be taken into account in vocabulary teaching. Reid (1987) states that sensory preference like visual, aural, tactile and kinesthetic need to be assessed while teaching vocabulary. Visually sound EFL learners are certain to enjoy visual imagery and semantic mapping whereas those good at aurally would prefer aural imagery. Likewise, various styles are preferred by learners individually. The other implication of the study is that EFL teachers should revisit the decontextualizing techniques such as word lists, flashcards and traditional use of dictionary. This may be done in the light of the findings of the present study and the suggestions given.

\section{References}

Alqahtani, M. (2015). The Importance of Vocabulary in Language Learning and How to BeTaught. International Journal of Teaching and Education, 3(3), 21-34.

Al-Hazemi, H. (1993). Low level EFL vocabulary tests for Arabic speakers. (Unpublished doctoral dissertation.) University of Wales, Swansea, UK.

Al-Homoud, F., \& Schmitt, N. (2009). Extensive reading in a challenging environment: A comparison of extensive and intensive reading approaches in Saudi Arabia. Language Teaching Research, 13, 383-401.

Altyari, A. W. (2017). English Vocabulary Uptake by Saudi Arabic Speaking Students at Public Schools. British Journal of English Linguistics, 5(1), 10-16.

Assah, A. (1969). Miracle of the desert kingdom. Dublin: Cahill \& Co., Ltd.

Baniabdelrahman, A. A., \& Al-shumaimeri, Y. (2014). Strategies Used by Saudi EFL Students to Determine the Meaning of English Words. English Language Teaching, 7(1), 75-92.

Crookall, D., \& Watson, R. (1985). Some applied and theoretical perspectives on a jigsaw reading exercise. ITL-International Journal of Applied Linguistics, 69(1), 43-78.

Carrell, P. L. (1984). The effects of rhetorical organization on ESL readers. TESOL quarterly, 18(3), 441-469.

Daller, H., Milton, J., \& Treffers-Daller, J. (Eds.). (2007). Modelling and assessing vocabulary knowledge. Cambridge, UK: Cambridge University Press.

Elttayef, A. I., \& Hussein, N. O. (2017). Arab Learners' Problems in Learning English Language: A Teacher Perspective. Journal of Literature, Languages and Linguistics, 40, 1-6.

Hague, S. A. (1987). Vocabulary instruction: What L2 can learn from L1. Foreign Language Annals, 20(3), 217-225.

Hudson, T. (1982). The effects intended schemata on the "short circuit" in L2 reading: Non decoding factors in L2 reading performance. Language learning, 32(1), 1-33.

McWilliam, N. (1998). What's in a Word?: Vocabulary development in multilingual 


\section{Macrothink \\ International Journal of English Language Education \\ ISSN 2325-0887 \\ 2020, Vol. 8, No. 1}

classrooms. Stylus Publishing, LLC.

Nation, P. (1990). Teaching and learning vocabulary. New York: Heinle \& Heinle.

Nation, P. (2001). Learning vocabulary in another language. Cambridge, UK: Cambridge University Press.

Nation, P. (2015). Principles Guiding Vocabulary Learning through Extensive Reading. Reading in a Foreign Language, 27(1), 136-145.

O'malley, J. M., O'Malley, M. J., Chamot, A. U., \& O'Malley, J. M. (1990). Learning strategies in second language acquisition. Cambridge university press.

Oxford, R., \& Crookall, D. (1990). Vocabulary learning: A critical analysis of techniques. TESL Canada Journal, 09-30.

Reid, J. M. (1987). The learning style preferences of ESL students. TESOL quarterly, 21(1), 87-111.

Schmitt, N. (2000). Vocabulary in Language Teaching. Cambridge: Cambridge University Press.

Richards, J. C., \& Singleton, D. (1999). Exploring the second language mental lexicon. Cambridge University Press.

Shen, Z. (2008). The roles of depth and breadth of vocabulary knowledge in EFL reading performance. Asian Social Science, 4(12), 135-137.

Stahl, S. A. (2003). Vocabulary and readability: How knowing word meanings affects comprehension. Topics in language disorders, 23(3), 241-247.

Stahl, S. A. (1999). Vocabulary development. Brookline Books.

Swaffar, J. K. (1988). Readers, texts, and second languages: The interactive processes. The Modern Language Journal, 72(2), 123-149.

Thornbury, S. (2002). How to teach vocabulary. Harlow: Longman.

Zimmerman, C. B. (1997). Historical trends in second language vocabulary instruction. Second language vocabulary acquisition, 6(1), 5-19.

\section{Copyright Disclaimer}

Copyright for this article is retained by the author(s), with first publication rights granted to the journal.

This is an open-access article distributed under the terms and conditions of the Creative Commons Attribution license (http://creativecommons.org/licenses/by/3.0/). 